\title{
Respiratory rate: measurement of variability over time and accuracy at different counting periods
}

\author{
E A F Simoes, R Roark, S Berman, L L Esler, J Murphy
}

\begin{abstract}
The respiratory rates/minute of 97 children were monitored every 10-15 minutes over one hour, by an observer and by pneumogram, at which times two 30 second and one 60 second counts were obtained. The children were under 5 years of age with lower respiratory tract infections $(n=20)$, upper respiratory tract infections $(n=34)$, or controls without acute respiratory infection $(n=43)$. The difference between respiratory rate count determined simultaneously by observation and pneumogram in relation to their mean count was analysed for the 60 second counting period, 30 plus 30 second period, and the 30 second period doubled. The mean difference for the 60 second period was 1.79 , for the 30 plus 30 second period 1.42 , and for the 30 second period doubled 1.72 . The variability between respiratory rate counts determined by observation and pneumogram was significantly lower in counts obtained when the subject was sleeping and higher when agitated compared with obtaining a count when the subject was awake and calm or feeding. The variability was also significantly lower in subjects with lower respiratory tract infections compared with those with upper respiratory tract infections and control subjects without respiratory symptoms. In the same patient, over the one hour, $50 \%$ of the 60 second counts varied by up to 14 breaths/minute and $75 \%$ by up to 21 breaths/minute. The least variability was seen in chidren with a lower respiratory tract infection, who tended to maintain their rapid breathing in contrast to those with an upper respiratory tract infection and controls without respiratory symptoms. About $10 \%$ of initial 30 second counts, $12 \%$ of 60 second, and $16 \%$ of initial and repeat 30 second attempts to obtain accurate counts failed. Failures occurred more frequently in children $<2$ months of age and those agitated. The data from this study suggest that one minute's counting either at a stretch or in two blocks of 30 second intervals is better than counting the respiratory rate for $\mathbf{3 0}$ seconds, when the child is either awake and calm or when asleep.
\end{abstract}

The World Health Organisation (WHO) Case Management Program for Acute Respiratory Infections uses respiratory rate thresholds and the presence of lower chest wall indrawing to decide if a patient has pneumonia and needs hospitalisation or outpatient antibiotics. ${ }^{1}$ Criteria for diagnosis of a lower respiratory infection include a respiratory rate of 60 or greater in infants under 2 months of age, 50 or greater in infants age 2 to 11 months, and 40 or greater in children 12 months and older. The presence of indrawing in a child without wheezing is an indication of severe disease requiring hospitalisation. The accuracy of diagnosis relies on the ability to obtain an accurate respiratory rate/minute and to recognise the presence or absence of lower chest wall indrawing. As this latter sign is fairly constant from patient to patient and its recognition can be taught easily (E A F Simoes, E McGrath, unpublished observation), obtaining an accurate respiratory rate count is the most important variable in the programme. As the respiratory rate depends on a single count, the natural variability in the rate may affect the classification of disease.

This study was undertaken to determine the optimal time period for counting the respiratory rate in children under 5 years of age and to determine factors that affect its variability over time. It has been suggested that a $\mathbf{3 0}$ second count, doubled, be used to obtain a respiratory rate. ${ }^{2}$ Because of the natural variability of the respiratory rate and the presence of periodic breathing in infants $<6$ months of age, ${ }^{3}$ a 60 secord count has been recommended by the WHO. ${ }^{1}$ One study that used three, 15 second counts with a stethoscope to obtain a respiratory rate, documented baseline rates over 50 breaths/ minute during the first six months of life ${ }^{4}$ It is possible that counting for a longer period of time might result in more failed attempts because of movement of the child, or other distractions. Hence the specific aims of this study were:

(1) To determine the accuracy of respiratory rate counting by comparing observer counts with those obtained from an electronic pneumogram for 30 second and 60 second counting intervals.

(2) To determine the effect of (i) the age, (ii) the illness, and (iii) the state of the child (that is, whether the child was sleeping, calm and awake, feeding, or agitated) on the accuracy of counting.

(3) To determine the natural variability in the respiratory rate over one hour.

(4) To determine how many attempts at obtaining a respiratory rate resulted in failures and identify the reasons for failures.

Subjects and methods

Subjects were prospectively enrolled in the study and consisted of children less than 5 years of age seen at three locations within the 
teaching hospital of the University of Colorado Health Sciences Center (UCHSC), including the paediatric outpatient department, the general paediatric inpatient ward, and the normal newborn nursery.

Eligibility criteria included parental consent, age less than 5 years, and illness (if present) of less than two weeks' duration. Exclusion criteria included presence of any chronic illness, the child having an illness which would likely involve dehydration, children who were inconsolably agitated, and presence of a current illness of greater than two weeks' duration. Subjects were enrolled on a first come basis without consideration given to sex or race. Parents of subjects were asked to read and sign a UCHSC Institutional Review Board approved consent form giving their permission for their child's participation in the study.

A medical history focusing on the child's current illness (if any) and a medical history (focusing particularly on any previous respiratory conditions) was then obtained. A physical examination was then performed that carefully assessed respiratory findings.

After enrolment into the study, standard paediatric silver/silver chloride electrodes were placed on the subject's mid-axillae at the costal margins and leads from an Aequitron 2916 respiratory/heart rate monitor were attached. The monitor was linked to a General Scanning RS2-5P strip chart recorder which produced real time traces of chest wall excursions on Aequitron 8285-12 $1 \mathrm{~mm}$ graduated strip paper.

The monitor and trace were switched on once the child had become quiet after any disturbance produced by application of the electrodes. A strip chart running rate of $1 \mathrm{~mm} / \mathrm{second}$ was used during periods when the observer was not counting the respiratory rate. Synchronous with the human observer beginning his respiratory rate count, the strip chart running rate was switched to $5 \mathrm{~mm} / \mathrm{second}$. This produced a trace pattern that very clearly delineated the beginning and end of the observer counting interval and allowed accurate counting on the strip. When movement artefact altered baseline recording, peaks and troughs of the respiratory excursion usually remained discernible. However, when movement artefact prevented accurate interpretation, the pneumogram was considered non-evaluable.

The observer counted the respiratory rate for 30 seconds, waited for a period of approximately one minute and repeated the above procedure counting instead for 60 seconds. After waiting again for one minute, another count of 30 seconds was made. The respiratory rate and state of the child (awake and calm, feeding, sleeping, and agitated), were recorded on a flow sheet. Mild agitation was defined as motion non-disruptive to counting; severe agitation disrupted counting and was considered a reason for failure. In addition, during each counting interval the observer recorded any counting attempts that failed and the reason for the failure (that is, crying, coughing, yawning, apnoea, deep sighs, severe agitation, feeding movements, and distraction or losing track of the time by the observer).
After obtaining this set of 30 second $/ 60$ second/30 second counts, the observer waited for 12-15 minutes before repeating the set of counts described above. These sets of counts were obtained five times for each subject evaluated. The counts on the strip chart were read by a blinded observer at the end of the study after all patients were enrolled.

The respiratory rate measurements are presented as the mean difference between the respiratory rate determined by observation and pneumogram and the SD of the difference. The agreement between the respiratory rate counts obtained by observation was compared with those obtained from an electronic pneumogram using the graphical technique of Bland and Altman. ${ }^{5}$ In addition, the resulting variances $\left(\mathrm{SD}^{2}\right)$ of the difference between rates from the two methods were compared between time intervals as well as between age groups, diagnoses, and child states with Bartlett's test for homogeneity of variance. Where a significant difference was found, pairwise comparisons, by means of an $F$ test for equality of variance, were carried out and reported.

The data for the counting failures are reported as the percentage of failures out of the total observations. These percentages were compared using the normal approximation to the test for equality of binomial proportions.

\section{Results}

\section{PATIENT POPULATION}

There were 97 patients studied, approximately equally distributed over the three age groups: less than 2 months $(n=27), 2-11$ months $(n=$ $37)$, and $12-48$ months $(n=33)$. The median age of children studied was 6 months and the mean age 10 months. Fifty one of these children were boys. Of the 97 children studied, 20 had lower respiratory tract infections, 34 upper respiratory tract infections, and 43 were controls who did not have any respiratory symptoms.

Of the 34 patients categorised as having an upper respiratory tract infection, 26 had uncomplicated viral upper respiratory infections, four had pharyngitis, three croup, and one influenza. For the purpose of the study, the three patients with croup were classified as having an upper respiratory infection. Of the 20 children with lower respiratory tract infections, 12 had bronchiolitis, four interstitial pneumonia (probably viral in aetiology), two a lobar pneumonia, one an aspiration pneumonia, and one pneumonia with effusion. Nineteen of these 20 patients had abnormal chest radiographs. In one child, a radiograph was not obtained.

\section{RESPIRATORY RATES ACCORDING TO METHOD} AND THE DURATION OF THE COUNTING PERIOD The numbers, ranges, and means (SD) of the respiratory rates determined simultaneously by observation and pneumogram are presented in table 1 for the initial 30 second, the 60 second, and repeat 30 second counts. The pneumogram tracing was non-evaluable in 12 of 1382 paired respiratory rate counts. 
Table 1 Respiratory rates according to method and duration of counting period

\begin{tabular}{lllclc}
\hline Method & Period & $\begin{array}{l}\text { No of } \\
\text { counts }\end{array}$ & Minimum & Maximum & Mean $(S D)$ \\
\hline Pneumogram & Initial 30 second & 458 & $10 \cdot 0$ & $43 \cdot 0$ & $22 \cdot 6(6 \cdot 3)$ \\
Observed & Initial 30 second & 462 & $7 \cdot 0$ & $42 \cdot 0$ & $21 \cdot 8(6 \cdot 5)$ \\
Pneumogram & 60 second & 459 & $19 \cdot 0$ & $90 \cdot 0$ & $44 \cdot 0(12 \cdot 3)$ \\
Observed & 60 second & 463 & $20 \cdot 0$ & $85 \cdot 0$ & $42 \cdot 2(11 \cdot 7)$ \\
Pneumogram & Repeat 30 second & 453 & $10 \cdot 0$ & $50 \cdot 0$ & $22 \cdot 4(6 \cdot 4)$ \\
Observed & Repeat 30 second & 457 & $9 \cdot 0$ & $52 \cdot 0$ & $21 \cdot 5(6 \cdot 5)$ \\
\hline
\end{tabular}

Table 2. Mean difference between 60 second observed and pneumogram respiratory rate counts by age, child state, and diagnosis

\begin{tabular}{|c|c|c|c|c|}
\hline \multirow[t]{2}{*}{ Characteristic } & \multirow{2}{*}{$\begin{array}{l}\text { Paired } \\
\text { observations }\end{array}$} & \multicolumn{2}{|l|}{ Range } & \multirow[t]{2}{*}{ Mean $(S D)$} \\
\hline & & Minimum & Maximum & \\
\hline $\begin{array}{l}\text { Age (months): } \\
<2 \\
2-11 \\
\geqslant 12\end{array}$ & $\begin{array}{l}134 \\
173 \\
148\end{array}$ & $\begin{array}{l}-17 \\
-16 \\
-15\end{array}$ & $\begin{array}{l}23 \\
37 \\
23\end{array}$ & $\begin{array}{l}1.5(6.4)(1) \\
1.9(7.6) \\
1.9(6.3)(1)\end{array}$ \\
\hline $\begin{array}{l}\text { Child state: } \\
\text { Calm/awake } \\
\text { Feeding } \\
\text { Sleeping } \\
\text { Agitated }\end{array}$ & $\begin{array}{r}162 \\
44 \\
142 \\
107\end{array}$ & $\begin{array}{l}-15 \\
-16 \\
-15 \\
-17\end{array}$ & $\begin{array}{l}37 \\
21 \\
17 \\
30\end{array}$ & $\begin{array}{l}2 \cdot 1 \quad(7 \cdot 2) \\
2 \cdot 3(6 \cdot 9) \\
1 \cdot 3(4 \cdot 7)(2) \\
1 \cdot 6(8 \cdot 5)(3)\end{array}$ \\
\hline $\begin{array}{l}\text { Diagnosis: } \\
\text { Lower respiratory tract infection } \\
\text { Upper respiratory tract infection } \\
\text { Control }\end{array}$ & $\begin{array}{r}96 \\
157 \\
202\end{array}$ & $\begin{array}{l}-11 \\
-15 \\
-17\end{array}$ & $\begin{array}{l}20 \\
37 \\
30\end{array}$ & $\begin{array}{ll}0.8 & (5 \cdot 3) \\
2 \cdot 0 & (7 \cdot 3)(4) \\
2 \cdot 0 & (7 \cdot 1)(4)\end{array}$ \\
\hline
\end{tabular}

Results of tests for equal variance: (1) $p<0.01$; variance significantly lower than age 2-11 months; (2) $p<0.01$; variance significantly lower than calm or feeding states; (3) $\mathrm{p}<0.05$; variance significantly higher than calm or feeding states; and $(4) \mathrm{p}<0.01$; variance lower than calm or feeding states; $(3) \mathrm{p}<0 \cdot 05$; variance signif
significantly higher than lower respiratory tract infection.

COMPARISON OF OBSERVER WITH PNEUMOGRAM RESPIRATORY RATE COUNTS

The differences between respiratory rate counts determined simultaneously by observation and pneumogram were plotted on a scattergram in relation to their mean count for the 60 second counting period, 30 plus 30 second period, and 30 second period doubled (figure). Two outlier observations were excluded from analysis as they were considered technical errors and did not change the values or significance of the differences. The mean difference (SD) was $1 \cdot 79$ $(6 \cdot 85)$ for the 60 second count, $1 \cdot 42(7 \cdot 21)$ for the 30 plus 30 second count, and $1 \cdot 72(8 \cdot 60)$ for the 30 second count doubled. The variance was significantly larger for the 30 second period doubled compared with the 60 second or 30 plus 30 second periods $(\mathrm{p}<0.01)$.

The influence of age $(<2$ months, 2-11 months, $\geqslant 12$ months), child state (calm and awake, feeding, agitated, and sleeping), and diagnosis (lower respiratory tract infection, upper respiratory tract infection, and controls) on the mean difference (SD) of paired pneumogram and observed 60 second respiratory rate counts is shown in table 2 . The variability between observed and pneumogram counts was higher for subjects 2-11 months of age than for younger or older subjects $(p<0.01)$. The variability between methods was lowest when the counting was done on a sleeping subject and highest when the subject was agitated. The counting during these two states were significantly different from counting when the subject was calm or feeding. There was no significant difference in variability between counting when the subject was calm versus feeding. The variability was also significantly lower when the subject had a lower compared with an upper

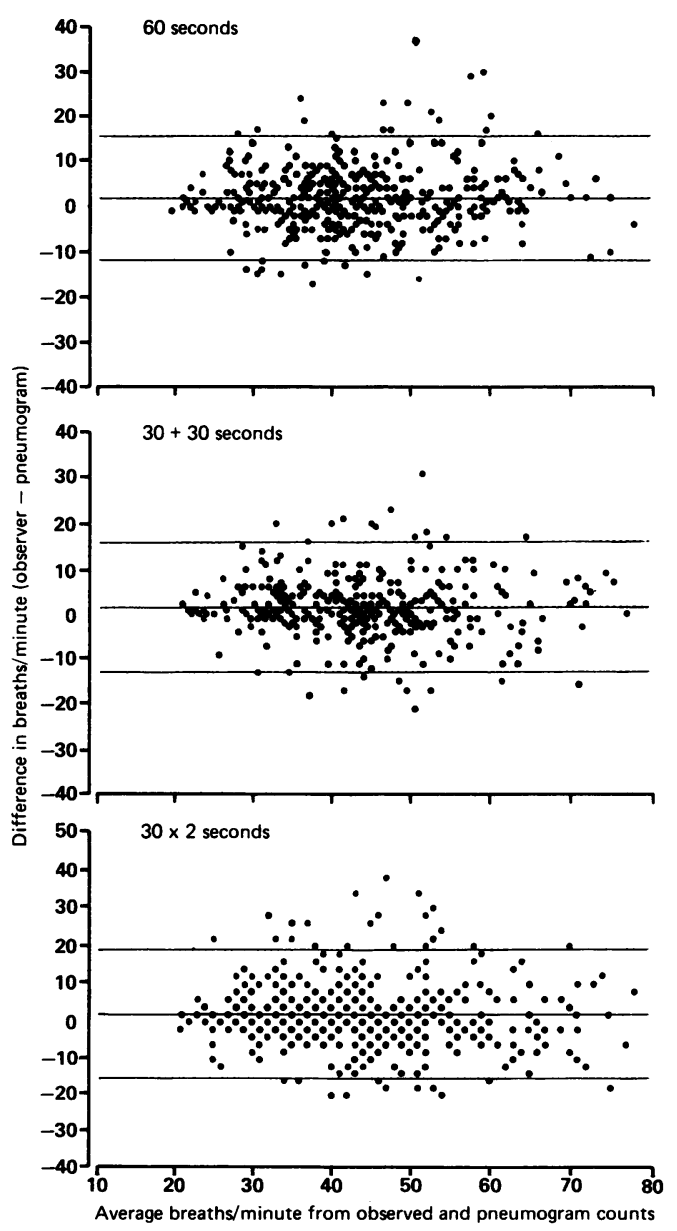

Differences between respiratory rate counts determined simultaneously by observation and pneumogram in relation to their mean counts for the different counting periods. The lines represent mean $(2 S D)$. Some points represent more than one observation. Two outliers were not shown. 
respiratory tract infection or no respiratory infection (control). There was no significant difference in variability in subjects with an upper respiratory tract infection compared with controls.

COMPARISON OF SEQUENTIALLY OBSERVED RESPIRATORY RATE COUNTS OBTAINED IN THE SAME CHILD STATE

Respiratory rate counts determined by observation during the initial 30 second, 60 second, and repeat 30 seconds of the same counting interval (all within five minutes) were analysed when the child remained in the same state during each counting period. The differences between mean and (SD) were analysed for the 60 second counting periods against 30 plus 30 second and 30 second doubled periods. The mean difference (SD) for 342 paired 60 second and 30 plus 30 second periods were $-0.96(6.5)$. The mean difference (SD) for 379 paired 60 second and 30 second doubled periods was $-0.92(7 \cdot 4)$. The variance was significantly greater between the 60 second and doubled 30 second count $(54 \cdot 8)$ than the 60 second and 30 plus 30 second $(42 \cdot 25)(\mathrm{p}<0 \cdot 01)$

\section{VARIABILITY OF THE RESPIRATORY RATE} OVER TIME

The mean (SD) difference in respiratory rates determined by 60 second observed counts between the minimum and maximum rate recorded over the one hour of observation and the 25th, 50th, and 75th centile distribution for the differences are shown in table 3 according to age, state of child, and diagnosis. Taking the whole group, the average difference between maximum and minimum recorded observed respirations was $15 \cdot 6$. Fifty percent had a variation of up to 14 respirations/minute and $75 \%$ up to 21 respirations/minute. Variability over time was greatest in (a) subjects between 2-11 months of age, (b) the presence of an upper respiratory tract infection and (c) the agitated state, but the difference in these variances were not significant.

\section{REASONS FOR FAILURES IN COUNTING THE} RESPIRATORY RATE

A failure was defined as any substantial interruption in the counting of the respiratory rate that would have rendered the count inaccurate. The distribution of failures in counting by age are tabulated according to counting period, child

Table 3 Variability over time: differences between maximum and minimum respiratory rates in patients counted over one hour of observation

\begin{tabular}{|c|c|c|c|c|c|}
\hline \multirow[t]{2}{*}{ Characteristics } & \multirow{2}{*}{$\begin{array}{l}\text { No of } \\
\text { subjects }\end{array}$} & \multirow[t]{2}{*}{ Mean (SD) } & \multicolumn{3}{|c|}{ Centiles } \\
\hline & & & $25 t h$ & Soth & $75 t h$ \\
\hline Whole group & 97 & $15 \cdot 6(9 \cdot 9)$ & 9 & 14 & 21 \\
\hline $\begin{array}{l}\text { Age (months): } \\
\quad<2 \\
2-11 \\
\geqslant 12\end{array}$ & $\begin{array}{l}27 \\
37 \\
33\end{array}$ & $\begin{array}{l}15 \cdot 1(9 \cdot 1) \\
19 \cdot 9(11 \cdot 5) \\
10 \cdot 8(5 \cdot 6)\end{array}$ & $\begin{array}{r}10 \\
10 \\
7\end{array}$ & $\begin{array}{l}17 \\
18 \\
10\end{array}$ & $\begin{array}{l}21 \\
25 \\
14\end{array}$ \\
\hline $\begin{array}{c}\text { Child state:* } \\
\text { Calm/awake } \\
\text { Feeding } \\
\text { Sleeping } \\
\text { Agitated }\end{array}$ & $\begin{array}{r}41 \\
9 \\
46 \\
31\end{array}$ & $\begin{aligned} & 8 \cdot 2(7 \cdot 8) \\
& 7 \cdot 4(6 \cdot 5) \\
& 7 \cdot 8(6 \cdot 0) \\
& 10 \cdot 0(5 \cdot 2)\end{aligned}$ & $\begin{array}{l}2 \\
4 \\
3 \\
7\end{array}$ & $\begin{array}{r}5 \\
6 \\
6 \\
10\end{array}$ & $\begin{array}{l}14 \\
12 \\
12 \\
13\end{array}$ \\
\hline $\begin{array}{l}\text { Diagnosis: } \\
\text { Lower respiratory tract } \\
\text { infection }\end{array}$ & 20 & $14 \cdot 0(10 \cdot 3)$ & $9 \cdot 5$ & 12 & $13 \cdot 5$ \\
\hline $\begin{array}{l}\text { Upper respiratory tract } \\
\text { infection } \\
\text { Control }\end{array}$ & $\begin{array}{l}34 \\
43\end{array}$ & $\begin{array}{l}17 \cdot 5(10 \cdot 6) \\
14 \cdot 6(9 \cdot 02)\end{array}$ & $\begin{array}{l}9 \\
7\end{array}$ & $\begin{array}{l}15 \\
16\end{array}$ & $\begin{array}{l}25 \\
21\end{array}$ \\
\hline
\end{tabular}

${ }^{*}$ Some patients were in more than one state over the one hour of observation.

Table 4 Frequency of counting failures according to counting period, child state, and diagnosis. Results are failure/total number of observations (\%)

\begin{tabular}{|c|c|c|c|c|}
\hline & \multicolumn{3}{|l|}{ Age (months) } & \multirow[t]{2}{*}{ Total } \\
\hline & $<2$ & $2-11$ & $\geqslant 12-48$ & \\
\hline $\begin{array}{l}\text { Counting period: } \\
1 \text { (60 sec) } \\
2(30+30 \mathrm{sec}) \\
3(30 \mathrm{sec} \times 2)\end{array}$ & $\begin{array}{l}26 / 160(16) \\
35 / 169(21) \\
25 / 159(16)\end{array}$ & $\begin{array}{l}20 / 196(10) \\
24 / 200(12) \\
14 / 190(7)\end{array}$ & $\begin{array}{l}18 / 170(11) \\
25 / 176(14) \\
10 / 161(6)\end{array}$ & $\begin{array}{l}64 / 526(12) \\
84 / 545(15) \\
49 / 510(10)\end{array}$ \\
\hline $\begin{array}{l}\text { Child state: } \\
\text { Calm/awake } \\
\text { Feeding } \\
\text { Sleeping } \\
\text { Agitated }\end{array}$ & $\begin{array}{l}9 / 89(10) \\
6 / 57(11) \\
23 / 241(10) \\
18 / 51(35)\end{array}$ & $\begin{array}{l}11 / 188(6) \\
4 / 65(6) \\
10 / 174(6) \\
15 / 122(12)\end{array}$ & $\begin{array}{l}14 / 272(5) \\
1 / 12(8) \\
3 / 59(5) \\
24 / 125(19)\end{array}$ & $\begin{array}{l}34 / 549(6) \\
11 / 134(8) \\
36 / 474(8) \\
57 / 355(16)\end{array}$ \\
\hline $\begin{array}{l}\text { Diagnosis: } \\
\text { Lower respiratory tract infection } \\
\text { Upper respiratory tract infection } \\
\text { Control }\end{array}$ & $\begin{array}{l}11 / 83(13) \\
18 / 62(29) \\
32 / 317(10)\end{array}$ & $\begin{array}{l}15 / 159(9) \\
18 / 250(7) \\
11 / 160(7)\end{array}$ & $\begin{array}{l}13 / 88(15) \\
13 / 212(6) \\
17 / 197(9)\end{array}$ & $\begin{array}{l}39 / 330(12) \\
49 / 524(9) \\
60 / 674(9)\end{array}$ \\
\hline Total & $61 / 462(13)$ & $44 / 569(8)$ & 43/497 (9) & $148 / 1528(10)$ \\
\hline
\end{tabular}


state, and diagnosis in table 4. Failures were significantly higher $(13 \%)$ in children less than 2 months old than in those above 2 months of age $(8 \%)(Z=4 \cdot 2, p<0.0001)$.

When the period of counting was taken as a criterion (namely 30 second doubled $v 60$ seconds $v$ the sum of two 30 seconds), it was found that there was no significant increase in the overall proportion of failures between the initial 30 second count and 60 second count $(Z=$ $1.03, p=0.3)$ or between 60 second and the sum of the two 30 second counts $(Z=1 \cdot 41, p=0 \cdot 16)$.

Overall, when the state of the child was considered, it was found that $16 \%$ of all observations resulted in counting failures when children were agitated. In contrast, when children were either awake or feeding or sleeping, the failure rate was between 6 to $8 \%(Z=5 \cdot 18$, $\mathrm{p}<0.0001)$. The presence of respiratory disease did not increase the number of failures. Reasons for failure were agitation (19\%), sighing (16\%), feeding (14\%), crying (13\%), observer distraction (9\%), yawning (9\%), coughing (3\%), and others (17\%).

\section{Discussion}

The primary goal of this study was to determine the most accurate time period for counting the respiratory rate by health workers. Studies of respiratory rate during infancy have used continuous electronic monitoring, ${ }^{3-8}$ auscultated counts, ${ }^{4}$ and observed counts. ${ }^{9} 10$ This work has been previously reviewed and we knew of no work that has compared observed and pneumogram counts or the effect of different counting time periods. ${ }^{11}$ In this regard, the first question that we attempted to answer was which of the three counting periods has the lowest variability when the patient's respiratory rate was measured by both observation and a pneumogram. In this analysis, the most accurate method had the least variability between the observed and pneumogram counts. We are not assuming that the pneumogram is more accurate than observations. Variability between observer counts and pneumogram counts was lower when the sum of two 30 second respiratory counts or 60 second counts were used relative to doubling a 30 second count.

It was recognised that the major factors that increased variability between a pneumogram and observed count was age between 2-11 months, an agitated state, and an upper respiratory tract infection. The variability was lowest in sleeping subjects and those with lower respiratory tract infections. Possible reasons are that children with lower respiratory tract infections had (a) more rapid respirations, (b) the presence of lower chest wall indrawing, and (c) less activity than controls.

The study found a range of variability of respiratory rate counts obtained over one hour of observation from 10.8 to $19 \cdot 9$. However, our study was not designed to determine the impact of this variability on the usefulness of respiratory rate thresholds to identify pneumonia in subjects with and without respiratory symptoms. The possibility that subjects with pneumonia are more likely to maintain a raised respiratory rate over the WHO threshold compared with other subjects is suggested by the results in table 3. This deserves further study with a larger sample size.

An important factor in determining the optimum method of counting the respiratory rate in children is the number of attempts that must be made before an acceptable count can be obtained. Overall, about $10 \%$ of all attempts to obtain a satisfactory respiratory count resulted in a failure. There was no significant difference found in the number of failures that occurred when different counting methods were used. However, there was a significantly higher number of failures in children under 2 months of age and in children who were agitated compared with those who were calm, asleep, or were feeding.

In conclusion, the data from this study suggests that one minute's counting either at a stretch or in two blocks of $\mathbf{3 0}$ second intervals is probably the optimum method for counting the respiratory rate, when the child is either awake and calm or when asleep. The respiratory rate taken when the child is in a state of agitation is the least accurate, the most variable, and has the largest number of failures. Consideration should be given to advising that the respiratory rate should not be taken in this state.

This study was supported by grants from the World Health Organisation, Geneva, Switzerland, and grant RR-69 from the General Clinical Research Center Program of the division of research, National Institutes of Health, Bethesda, Maryland, USA.

1 World Health Organisation. Fourth programme report, 1988-1989. ARI programme for control of acute respiratory infections. Geneva: WHO, 1990;7:31.

2 Seidel HM, Ball JW, Paris JE, Beneded AW, eds. Chest and lungs. Mosby's guide to physical examination. St Louis: CV Mosby, 1987:245-75.

3 Richards JM, Alexander JR, Shinebourne EA, et al. Sequential 22-hour profiles of breathing patterns and heart rate in 110 full-term infants during their first 6 months of life. 110 full-term infants during
Pediatrics 1984;74:763-77.

4 Morley CJ, Thornton AJ, Fowler MA, et al. Respiratory rate and severity of illness in babies under 6 months old. Arch Dis Child 1990;65:834-7.

5 Bland JM, Altman DG. Statistical methods for assessing agreement between two methods of clinical measurement. Lancet 1986; : $307-10$.

6 Hoppenbrouwers T, Harper RM, Hodgman JE, et al. Polygraphic studies of normal infants during the first six months of life. II. Respiratory rate and variability as a function of state. Pediatr Res 1978;12:120-5.

7 Curzi-Dascalova L, Gaudebout C, Dreyfus-Brisac C. Respiratory frequencies of sleeping during the first months of life: correlation between values in different sleep states. Early Correlation between values

8 Ashton $\mathrm{R}$, Connoly $\mathrm{K}$. The relation of respiratory rate and heart rate to sleep states in the human newborn. Dev Med heart rate to sleep states in

9 Cherian T, John TJ, Simoes EAF, Steinhoff MC, John M. Evaluation of simple clinical signs for the diagnosis of acute Evaluation of simple clinical signs for the diagnosis of
lower respiratory tract infection. Lancet 1988;ii: 125-8

10 Campbell H, Bypass P, Greenwood BM. Simple clinical signs for diagnosis of actue lower respiratory infections. Lancet 1988;ii:742-3.

11 Berman S, Simoes EAF, Lanata C. Respiratory rate and pneumonia in infancy. Arch Dis Child 1991;66:81-4. 